\title{
Adjuvant treatment with EGFR TKI in resected non-small cell lung cancer with EGFR mutation: all that glitters is not gold!
}

\author{
Alfonso Fiorelli ${ }^{1}$, Fabiana Vitiello ${ }^{2}$, Floriana Morgillo ${ }^{3}$, Rosa Maria Di Crescenzo ${ }^{4}$, Andrea Bianco ${ }^{5}$, \\ Mario Santini ${ }^{1}$, Marina Di Domenico ${ }^{6}$ \\ ${ }^{1}$ Thoracic Surgery Unit, University of Campania “Luigi Vanvitelli”, Naples, Italy; ${ }^{2}$ Oncology Unit, Monaldi Hospital, Naples, Italy; ${ }^{3}$ Oncology Unit, \\ University of Campania "Luigi Vanvitelli”, Naples, Italy; ${ }^{4}$ Pathology Unit, Federico II University of Naples, Italy; ${ }^{5}$ Pneumology Unit, University of \\ Campania "Luigi Vanvitelli”, Naples, Italy; ${ }^{6}$ Pathology Unit, University of Campania "Luigi Vanvitelli”, Naples, Italy \\ Correspondence to: Alfonso Fiorelli, MD, PhD. Thoracic Surgery Unit, Universitàdella Campania "Luigi Vanvitelli”, Piazza Miraglia, 2, I-80138 \\ Naples, Italy. Email: alfonso.fiorelli@unicampania.it. \\ Comment on: Liang W, Cai K, Chen C, et al. Society for Translational Medicine consensus on postoperative management of EGFR-mutant lung \\ cancer (2019 edition). Transl Lung Cancer Res 2019;8:1163-73.
}

Submitted Mar 29, 2020. Accepted for publication Apr 09, 2020.

doi: $10.21037 / \mathrm{atm} .2020 .04 .57$

View this article at: http://dx.doi.org/10.21037/atm.2020.04.57

Lung cancer is the leading cause of cancer death, accounting for $\geq 1.35$ million deaths per annum worldwide, and $\geq 350,000$ deaths per annum in Europe (1). Non-small cell lung cancer (NSCLC) is the most common histology, accounting for approximately $85 \%$ of lung cancers. Surgery is the only curative treatment for NSCLC, but only $25-$ $30 \%$ of patients with NSCLC are eligible for surgery at time of diagnosis $(2,3)$. The 5 -year survival rates following NSCLC resection depend on pathological stage and range from $90 \%$ (stage IA1) to $41 \%$ (stage IIIA) $(4,5)$. Because of systemic micro-metastases present at time of surgery, many patients will relapse and will need adjuvant therapies (6). In the last years, advances in under standing molecular basis of cancer (REF), has led to development of more effective targeted therapies for patients with advanced NSCLC (7-9). In light of these results, several trials (10-12) have mostly focused on tyrosine kinase inhibitors (TKI) targeting the epidermal growth factor receptor (EGFR) for NSCLC harboring EGFR mutation after surgical resection. However, the efficacy of adjuvant treatment with EGFR TKIs in resected NSCLC is still under debate as EGFR-TKI has failed to significantly improve outcome in two trials $(10,11)$, except gefitinib among Chinese patients with EGFR mutation-positive NSCLC (12). Overall, the results of these studies suggest that, even in the early stages, adjuvant treatment with EGFR-TKI may be effective only in those patients whose tumor expresses an EGFR activating mutation. However, in the absence of efficacy data in terms of overall survival, at present, molecular target drugs cannot be recommended in the adjuvant treatment of NSCLC outside clinical trials. Thus, the Chinese Society for Translational Medicine (13) reviewed the current evidences published in literature, aiming to provide "strong" or "weak" recommendations on the following controversial issues (I) routine evaluation of EGFR mutation in all patients resected for non-squamous NSCLC; (II) EGFRTKI as standard of care in EGFR-mutant NSCLC patients undergoing surgery; (III) annual follow-up with brain MRI and bone scans in addition to regular chest CT scan; and (IV) osimertinib as first-line treatment in patients experiencing postoperative recurrence and metastasis. Several experts from different parts of the world were then invited to review these recommendations, and gave their criticisms.

First, EGFR mutation should be routinely evaluated in all patients resected for non-squamous NSCLC (strong recommendation). However, 6 out of 11 invited experts did not agree, and supported the routine evaluation of EGFR mutation profiling only in selected cases such as patients with locally advanced disease or patients with recurrence. In our opinion, this issue remains under debate based on the 
current literature. The European and Japanese Guidelines did not recommend the routine use of EGFR-TKI as adjuvant treatment in patients resected for NSCLC (14). Yet, RADIANT (10), and EVAN (11), despite an increase of disease free survival, did not show a proven improvement of overall survival with adjuvant EGFR TKIs in resected NSCLC.

Second, platinum-based chemotherapy is still the standard of care for EGFR-mutant NSCLC patients who require adjuvant systemic therapy after resection, and EGFR TKIs could not replace it (strong recommendation). All invited experts confirmed the role of cisplatinbased adjuvant chemotherapy as the standard of care for patients with resected NSCLC, irrespective of any tumour mutational status and we agree with this recommendation based on the results of several studies and meta-analyses $(15,16)$, and Randomized Controlled Trials $(17,18)$. Despite ADJUVANT study (12) demonstrated the significant benefits of adjuvant EGFR-TKI treatment, we believe that these results should be evaluated with caution before drawing definitive conclusions for the following reasons: (I) disease free survival in ADJUVANT study was much shorter than in other trials; (II) it is well known that pneumonectomy is associated with higher morbidity and mortality compared to lesser resection such as lobectomy or sublobar resection $(19,20)$. However, ADJUVANT study compared to other studies presented a lower rate of patients undergoing pneumonectomy (3 vs. 25\%); (III) in ADJUVANT study the median number of chemotherapy cycles received was four, and dose reductions were not clearly defined while in previous studies the planned four cycles was completed only in about $60 \%$ of patients; (IV) in ADJUVANT study, the pattern of relapses was not reported, despite EGFR mutated patients presenting a higher incidence of brain and bone metastases than control population. Furthermore, both the gefitinib and chemotherapy group presented similar 3-year diseasefree survival. On the other hand, EGFR TKIs could be a valuable alternative in patients who are considered at highrisk for standard chemotherapy and that the administration period of EGFR TKIs should be not less than 2 years.

Third, since EGFR-mutated patients had an increased risk of systemic disease including bone and brain metastases, brain MRI and bone scans as a supplement to chest CT scan should be performed every year (strong recommendation). By contrast, all experts recommended intensive followup with brain MRI and bone scans only in selected cases such as patients with Stage III or those with clinical symptoms suggestive of metastatic relapse, and we agreed with this recommendation. Guidelines from different scientific societies suggest only physical examination every 3 months [American Society of Clinical Oncology (ASCO)] or annual CT scan as stated by the American College of Radiology (ACR), National Comprehensive Cancer Network (NCCN), American College of Chest Physicians (ACCP), and European Society Medical Oncology (ESMO) (21). In fact, there is no evidence that an early detection of metastatic relapse significantly influences overall survival and an intensive surveillance programme is certainly more expensive (22).

Fourth, Osimertinib should be the preferred first-line treatment in patients with postoperative recurrence and metastasis (strong recommendation). Nine out of 10 invited experts were in agreement with this recommendation based on the results of FLAURA trial (23), reporting better overall survival, and lower toxicities of osimertinib compared to first- or second-generation EGFR-TKIs (i.e., gefitinib, erlotinib or afatinib). Only one expert suggested that FLAURA results (22) should not be generalized to all patients since the survival benefit was mostly observed in patients with stage IV disease, but not for patients with recurrence after resectable lung cancer. As osimertinib is more expensive than first- or second-generation EGFR-TKIs, three experts, we supported the need for evaluation of EGFR exon 19 del or L858R mutation by re-examination of tissue or liquid biopsy at the time of recurrence before starting treatment with Osimertinib to determine the feasibility of this treatment. In our opinion, Osimertinib should be considered as the first-line treatment in EGFR-mutated patients with postoperative recurrence and metastasis. In FLAURA study, the better ProgressionFree survival (PFS) of osimertinib compared with the firstgeneration EGFR-TKIs was confirmed across all predefined subgroups, including specific types of EGFR mutations (exon 19 deletion and exon $21 \mathrm{~L} 858 \mathrm{R}$ point mutation) and the presence or absence of baseline brain metastases. Yet, osimertinib was better tolerated than first generation TKIs since it was associated with lower rates of grade 3-4 adverse events than other EGFR-TKIs (34\% vs. 45\%), respectively. Thus, it may be particularly indicated in patients who may be debilitated due to surgical resection of lung cancer.

In conclusion, the recommendations of Chinese Society for Translational Medicine (13) are an additional armamentarium to physicians when selecting patients with resected NSCLC and EGFR mutation to identify those who will benefit from adjuvant treatment with EGFR TKIs. 


\section{Acknowledgments}

Funding: None.

\section{Footnote}

Provenance and Peer Review: This article was commissioned by the editorial office, Annals of Translational Medicine. The article did not undergo external peer review.

Conflicts of Interest: All authors have completed the ICMJE uniform disclosure form (available at http://dx.doi. org/10.21037/atm.2020.04.57). The authors have no conflicts of interest to declare.

Ethical Statement: The authors are accountable for all aspects of the work in ensuring that questions related to the accuracy or integrity of any part of the work are appropriately investigated and resolved.

Open Access Statement: This is an Open Access article distributed in accordance with the Creative Commons Attribution-NonCommercial-NoDerivs 4.0 International License (CC BY-NC-ND 4.0), which permits the noncommercial replication and distribution of the article with the strict proviso that no changes or edits are made and the original work is properly cited (including links to both the formal publication through the relevant DOI and the license). See: https://creativecommons.org/licenses/by-nc-nd/4.0/.

\section{References}

1. Malvezzi M, Bertuccio P, Levi F, et al. European cancer mortality predictions for the year 2013. Ann Oncol 2013;24:792-800.

2. Lang-Lazdunski L. Surgery for non small cell lung cancer. Eur Respir Rev 2013;22:382-404.

3. Fiorelli A, Sagan D, Mackiewicz L, et al. Incidence, Risk Factors, and Analysis of Survival of Unexpected N2 Disease in Stage I Non-Small Cell Lung Cancer. Thorac Cardiovasc Surg 2015;63:558-67.

4. Fiorelli A, Santini M. In lung cancer patients where a malignant pleural effusion is found at operation could resection ever still be justified? Interact Cardiovasc Thorac Surg 2013;17:407-12.

5. Pirker R, Filipits M. Adjuvant Therapy in Patients With Completely Resected Non-small-cell Lung Cancer: Current Status and Perspectives. Clin Lung Cancer
2019;20:1-6.

6. Fiorelli A, Rizzo A, Messina G, et al. Correlation between matrix metalloproteinase 9 and 18F-2-fluoro-2deoxyglucose-positron emission tomography as diagnostic markers of lung cancer. Eur J Cardiothorac Surg 2012;41:852-60.

7. Cattaneo F, Guerra G, Parisi M, et al. Expression of Formyl-peptide Receptors in Human Lung Carcinoma. Anticancer Res 2015;35:2769-74.

8. Di Zazzo E, Polito R, Bartollino S, et al. Adiponectin as Link Factor between Adipose Tissue and Cancer. Int J Mol Sci 2019;20:839.

9. Nigro E, Imperlini E, Scudiero O, et al. Differentially expressed and activated proteins associated with non small cell lung cancer tissues. Respir Res 2015;16:74.

10. Kelly K, Altorki NK, Eberhardt WE, et al. Adjuvant Erlotinib Versus Placebo in Patients With Stage IBIIIA Non-Small-Cell Lung Cancer (RADIANT): A Randomized, Double-Blind, Phase III Trial. J Clin Oncol 2015;33:4007-14.

11. Yue D, Xu S, Wang Q, et al. Erlotinib versus vinorelbine plus cisplatin as adjuvant therapy in Chinese patients with stage IIIA EGFR mutation-positive non-small-cell lung cancer (EVAN): a randomised, open-label, phase 2 trial. Lancet Respir Med 2018;6:863-73.

12. Zhong WZ, Wang Q, Mao WM, et al. Gefitinib versus vinorelbine plus cisplatin as adjuvant treatment for stage II-IIIA (N1-N2) EGFR-mutant NSCLC (ADJUVANT/ CTONG1104): a randomised, open-label, phase 3 study. Lancet Oncol 2018;19:139-48.

13. Liang W, Cai K, Chen C, et al. Society for Translational Medicine consensus on postoperative management of EGFR-mutant lung cancer (2019 edition). Transl Lung Cancer Res 2019;8:1163-73.

14. Majem M, Juan O, Insa A, et al. SEOM clinical guidelines for the treatment of non-small cell lung cancer (2018). Clin Transl Oncol 2019;21:3-17.

15. Kris MG, Gaspar LE, Chaft JE, et al. Adjuvant Systemic Therapy and Adjuvant Radiation Therapy for Stages I to IIIA Resectable Non-Small-Cell Lung Cancers: American Society of Clinical Oncology/Cancer Care Ontario Clinical Practice Guideline Update Summary. J Oncol Pract 2017;13:449-51.

16. Ettinger DS, Wood DE, Aisner DL, et al. Non-Small Cell Lung Cancer, Version 5. 2017, NCCN Clinical Practice Guidelines in Oncology. J Natl Compr Canc Netw 2017;15:504-35.

17. Wakelee HA, Dahlberg SE, Keller SM, et al. Adjuvant 
chemotherapy with or without bevacizumab in patients with resected non-small-cell lung cancer (E1505): an openlabel, multicentre, randomised, phase 3 trial. Lancet Oncol 2017;18:1610-23.

18. Douillard JY, Rosell R, De Lena M, et al. Adjuvant vinorelbine plus cisplatin versus observation in patients with completely resected stage IB-IIIA non-small-cell lung cancer (Adjuvant Navelbine International Trialist Association [ANITA]): a randomised controlled trial. Lancet Oncol 2006;7:719-27.

19. Fiorelli A, Vicidomini G, Milione R, et al. The effects of lung resection on physiological motor activity of the oesophagus. Eur J Cardiothorac Surg 2013;44:250-6.

20. Andreetti C, Menna C, D'Andrilli A, et al. Multimodal Treatment for Post-Pneumonectomy Bronchopleural

Cite this article as: Fiorelli A, Vitiello F, Morgillo F, Di Crescenzo RM, Bianco A, Santini M, Di Domenico M. Adjuvant treatment with EGFR TKI in resected non-small cell lung cancer with EGFR mutation: all that glitters is not gold! Ann Transl Med 2020;8(18):1199. doi: 10.21037/ atm.2020.04.57
Fistula Associated With Empyema. Ann Thorac Surg 2018;106:e337-9.

21. Crinò L, Weder W, van Meerbeeck J, et al. ESMO Guidelines Working Group. Early stage and locally advanced (non-metastatic) non-small-cell lung cancer: ESMO Clinical Practice Guidelines for diagnosis, treatment and follow-up. Ann Oncol 2010;21:v103-15.

22. Benamore R, Shepherd FA, Leighl N, et al. Does intensive follow-up alter outcome in patients with advanced lung cancer? J Thorac Oncol 2007;2:273-81.

23. Ramalingam SS, Gray JE, Ohe Y, et al. Osimertinib vs comparator EGFR-TKI as first-line treatment for EGFRm advanced NSCLC (FLAURA): Final overall survival analysis. Ann Oncol 2019;30:v914-5. 